\title{
Comparison of outcomes between endoscopic and microscopic transsphenoidal surgery for the treatment of pituitary adenoma: a meta-analysis
}

\author{
Xiaolin Chen, Wei Huang, Hongjuan Li, Yan Huan, Guoying Mai, Luming Chen, Hongqiang Huang, \\ Haoxiang Xu
}

The Second Clinical College of Guangzhou University of Chinese Medicine, Guangzhou, China

Contributions: (I) Conception and design: X Chen; (II) Administrative support: W Huang, H Li; (III) Provision of study materials or patients: Y Huan,

G Mai, L Chen; (IV) Collection and assembly of data: X Chen, W Huang, H Li; (V) Data analysis and interpretation: X Chen, W Huang, H Li; (VI)

Manuscript writing: All authors; (VII) Final approval of manuscript: All authors.

Correspondence to: Hongqiang Huang. The Second Clinical College of Guangzhou University of Chinese Medicine, Guangzhou, China.

Email: hhqiang1888@163.com.

Backgroundk Pituitary tumors are among the most common intracranial tumors. Surgical resection is
the most effective treatment for patients with pituitary tumors. Microscopic transsphenoidal surgery has
become the first-choice surgical approach to treating this malignancy, although it has certain limitations.
Neuroendoscopy has also been widely used for pituitary tumor surgery in recent years. This study aimed to
compare the efficacy and safety of these two surgical options for the treatment of pituitary tumors.
Methods: We conducted a literature search of the PubMed, Embase, Cochrane Controlled Center
Register of Controlled Trials (CENTRAL), Web of Science database, Google Scholar, and Baidu Scholar.
Relevant articles published up to September 25, 2020 were retrieved and then meta-analyzed using RevMan
software 5.1.

Results: A total of 29 case-control studies involving 7,774 patients were included in the meta-analysis. There was no significant difference in gross tumor removal (GTR) ( $R R=1.11$, 95\% CI: 0.97-1.26, P=0.12) or hormone excess secretion (HES) remission ( $\mathrm{RR}=1.08$, 95\% CI: $0.97-1.21, \mathrm{P}=0.16$ ) between the two groups. Endoscopic transsphenoidal surgery was associated with a lower incidence of diabetes insipidus (DI) than was microscopic transsphenoidal surgery ( $R R=0.76,95 \% \mathrm{CI}$ : 0.60-0.97, P=0.03).

Conclusions: Endoscopic transsphenoidal surgery does not significantly improve GTR or HES remission, but it can reduce the incidence of DI without increasing the rates of other complications.

Keywords: Pituitary tumor, endoscopy, meta-analysis

Submitted Oct 19, 2020. Accepted for publication Dec 08, 2020.

doi: 10.21037 /gs-20-851

View this article at: http://dx.doi.org/10.21037/gs-20-851

\section{Introduction}

Pituitary tumors comprise $10 \%$ of intracranial tumors, placing them among the most common malignancies of the brain (1). The main clinical manifestations of pituitary tumor are hormone over-secretion and tumor compression. Treatment methods include drug therapy, radiation therapy, and surgery, with surgical resection being the most effective treatment. However, the pituitary tumor is located deep in the pituitary fossa, adjacent to important structures such as the hypothalamus, cavernous sinus, and internal carotid artery, which limits the visual field and makes tumor removal using traditional surgical methods risky. Transsphenoidal resection was first proposed as a treatment for pituitary adenomas by Schloffer in January 1907 (2). Since 1960, transsphenoidal surgery under a microscope has become the first-choice approach for patients who require 
intrasellar surgery. The success rate of surgery is high, while the risk and incidence of complications are low. However, surgery still has certain limitations, especially the poor visibility.

With the development of endoscopic technology, surgery has entered a new era. In 1992, Jankowski was the first to apply endoscopy in pituitary tumor surgery (3). The lens angle of the neuroendoscope can be changed to provide a wider operative field of view, facilitating better observation. The anatomic area exposed by the endoscope is anterior to the optic chiasm, lateral to the lateral wall of the cavernous sinus, and posterior to the end of the basilar artery. In 2007, Laufer et al. concluded that endoscopic surgery is safe for transsphenoidal enlargement surgery (4).

In recent years, a number of studies have compared the efficacy and safety of the neuroendoscopic and microscopic transsphenoidal approaches in the treatment of pituitary tumor, but the results have been inconsistent. In order to determine the effectiveness of the neuroendoscopic transsphenoidal approach in pituitary tumor treatment, a meta-analysis of all available studies published to date was conducted to comprehensively evaluate the efficacy and safety of neuro-endoscopic transsphenoidal approach in patients with pituitary tumors. We present the following article in accordance with the PRISMA reporting checklist (available at http://dx.doi.org/10.21037/gs-20-851).

\section{Methods}

\section{Literature search}

We conducted a literature search of PubMed, Embase, Cochrane Controlled Center Register of Controlled Trials (CENTRAL), Web of Science database, Google Scholar, and Baidu Scholar. The reference lists of retrieved literature were also searched to identify any relevant articles. The databases were searched from inception to August 25, 2020, and there were no language restrictions. The search strategy was formulated with reference to the Cochrane Handbook. English keywords used for searches included "pituitary tumor", "Cushing syndrome", "Cushing disease", "Acromegaly", "pituitary adenomas", "microscopic*", "endoscopic", "transsphenoidal”".

\section{Inclusion and exclusion criteria}

The inclusion criteria were: (I) publicly published casecontrol studies; (II) study subjects were patients with pituitary tumors aged $>18$ years; (III) the experimental group was treated with neuro-endoscopic transsphenoidal pituitary tumor resection, and the control group was treated with microscopic transsphenoidal pituitary tumor resection; (IV) the study outcome indicators included: gross tumor removal (GTR); hormone excess secretion (HES) remission; the incidence of adverse reactions, including cerebrospinal fluid (CSF) leakage, diabetes insipidus (DI), epistaxis, hypopituitarism, meningitis, overall complications, visual improvement, and vision loss. Articles that did not meet the inclusion criteria, articles that did not include the main outcome indicators, or without a response from the author, or published repeatedly were excluded.

\section{Information and data extraction}

The full texts of the retrieved studies were read to obtain the general study characteristics, as well as the inclusion criteria, basic information of the study subjects, intervention measures, follow-up time, and main results. For data that could not be obtained from the published studies, we contacted the authors via email. The studies were read and the data were extracted by two authors independently. Any inconsistency or disagreement that arose regarding the data was resolved through discussion. If after a discussion, a consensus still had not been reached, a third reviewer was consulted for their opinion.

\section{Literature quality evaluation}

Two researchers evaluated the included literature according to the Newcastle-Ottawa Scale (NOS) (5). This quality evaluation standard includes seven items across the following three domains: (I) selection of the study population: whether the case determination was appropriate; representativeness of the cases; selection of the controls, and determination of the controls; (II) comparability between groups: consideration of the comparability of cases and controls in the study design and statistical analysis; and (III) measurement of exposure factors: determination of the exposure factors; whether the same method was used to determine the exposure factors of the cases and controls; and the non-response rate.

\section{Statistical methods}

The meta-analysis was performed using RevMan5.1 
software (Cochrane Center, London, England), available from Cochrane. Heterogeneity among the studies was analyzed using the $\chi^{2}$ test and $\mathrm{I}^{2}$ test. If the homogeneity between studies was good $\left(\mathrm{I}^{2}<50 \%, \mathrm{P}>0.1\right)$, the fixed-effects model was adopted; otherwise, the random-effects model was used. When clinical data could not be meta-analyzed, descriptive analysis was carried out.

\section{Results}

\section{Literature search results}

The initial search retrieved 577 articles, and after the elimination of duplicates with EndNote software, 443 articles remained. After the titles, abstracts, and full texts of these articles had been read, 29 articles that met the inclusion criteria were finally included in the meta-analysis and are shown in Table 1. The literature screening flowchart is displayed in Figure 1.

\section{General characteristics of the included articles}

A total of 29 studies, involving 4,557 patients, were included in this meta-analysis. All of the studies were designed as case-control studies and were published between 1999 and 2020. Patient populations mainly comprised Europeans, North Americans, and South Americans. Major countries involved in these studies included the United States, the United Kingdom, India, Canada, Italy, Finland, Iran, Norway, Belgium, North Korea, France, and China. The general information of the included articles is shown in Table 1.

\section{Quality evaluation}

The results of the quality evaluation of the included articles are shown in Table 2.

\section{Meta-analysis results}

\section{Gross tumor removal}

Fourteen studies reported the total tumor resection rates of endoscopic transsphenoidal resection and microscopic transsphenoidal resection in patients with pituitary tumors. The results showed that there was no significant difference in the tumor total resection rate between the endoscopic surgery group and the microscopic surgery group (RR
$=1.11,95 \%$ CI: 0.97-1.26, P=0.12, Figure 2).

\section{Hormone excess secretion remission}

Ten studies reported the remission rates of hormone oversecretion in patients with pituitary tumors who underwent endoscopic or microscopic transsphenoidal resection. The results showed that there was no significant difference in the remission rate of hormone over-secretion between the endoscopic surgery group and the microscopic surgery group (RR =1.08, 95\% CI: 0.97-1.21, $\mathrm{P}=0.16$, Figure 3).

\section{Overall complications}

Nine studies reported the total complication rates of endoscopic transsphenoidal resection and microscopic transsphenoidal resection in patients with pituitary tumors. The results revealed no significant difference in the overall complication rate between the endoscopic surgery group and the microscopic surgery group $(\mathrm{RR}=0.82,95 \% \mathrm{CI}$ : $0.54-1.23, \mathrm{P}=0.34$, Figure 4).

\section{Cerebrospinal fluid leakage}

Twenty-five studies reported the incidence of postoperative CSF leakage in patients with pituitary tumors who underwent endoscopic transsphenoidal resection or microscopic transsphenoidal resection. The results showed no significant difference in the incidence of CSF leakage between the endoscopic surgery group and the microscopic surgery group $(\mathrm{RR}=1.06,95 \% \mathrm{CI}$ : $0.88-1.28, \mathrm{P}=0.51$, Figure 5).

\section{Diabetes insipidus}

Twenty studies reported the incidence of postoperative DI in patients with pituitary tumors who underwent endoscopic transsphenoidal resection or microscopic transsphenoidal resection. The results revealed the incidence of DI in the endoscopic surgery group to be significantly lower than that in the microscopic surgery group, and the difference was statistically significant ( $\mathrm{RR}=0.76,95 \% \mathrm{CI}: 0.60-0.97$, $\mathrm{P}=0.03$, Figure 6).

\section{Epistaxis}

Five studies reported the incidence of postoperative epistaxis in patients with pituitary tumors who underwent endoscopic transsphenoidal resection or microscopic transsphenoidal resection. The results showed no significant difference in the incidence of epistaxis between the endoscopic surgery 


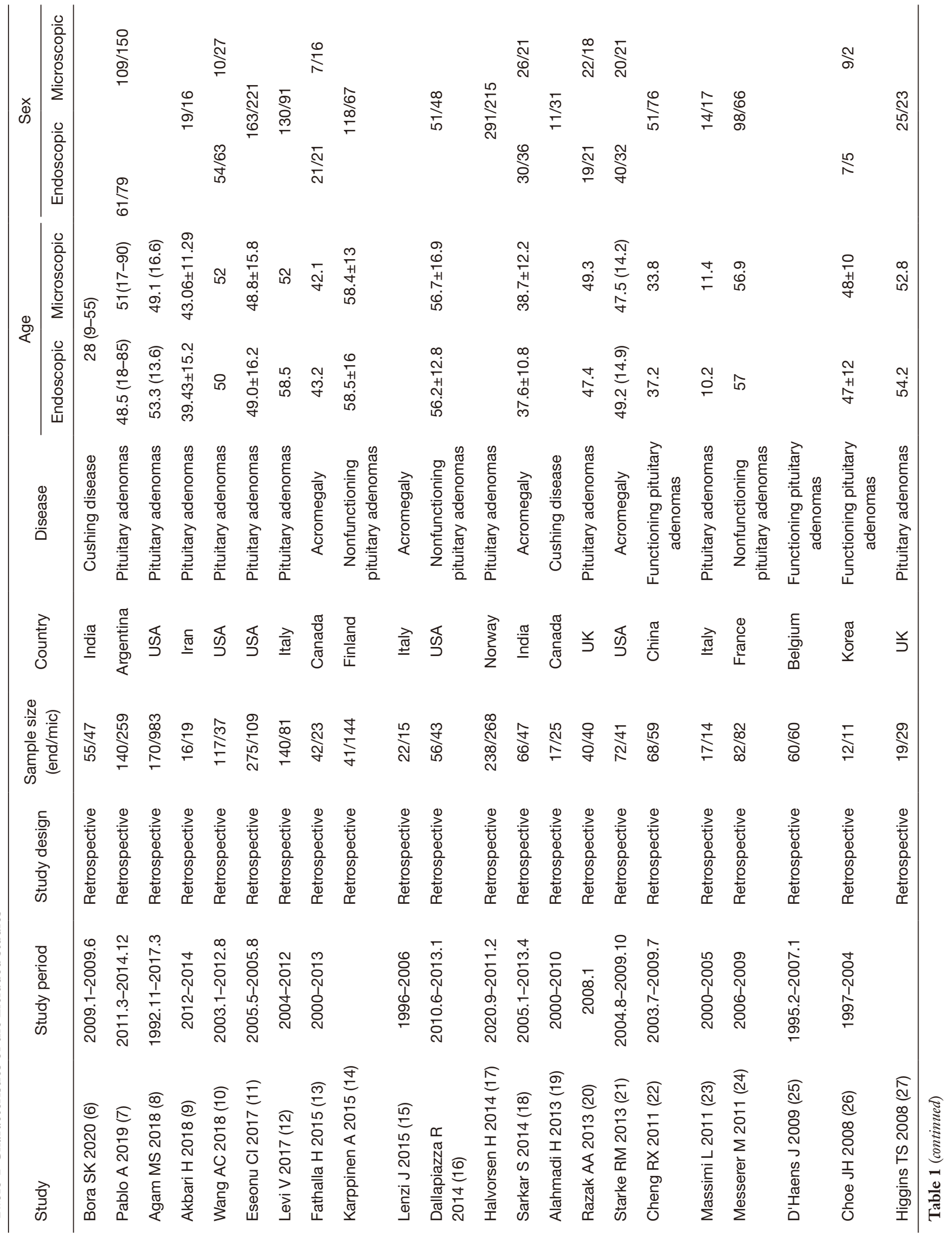




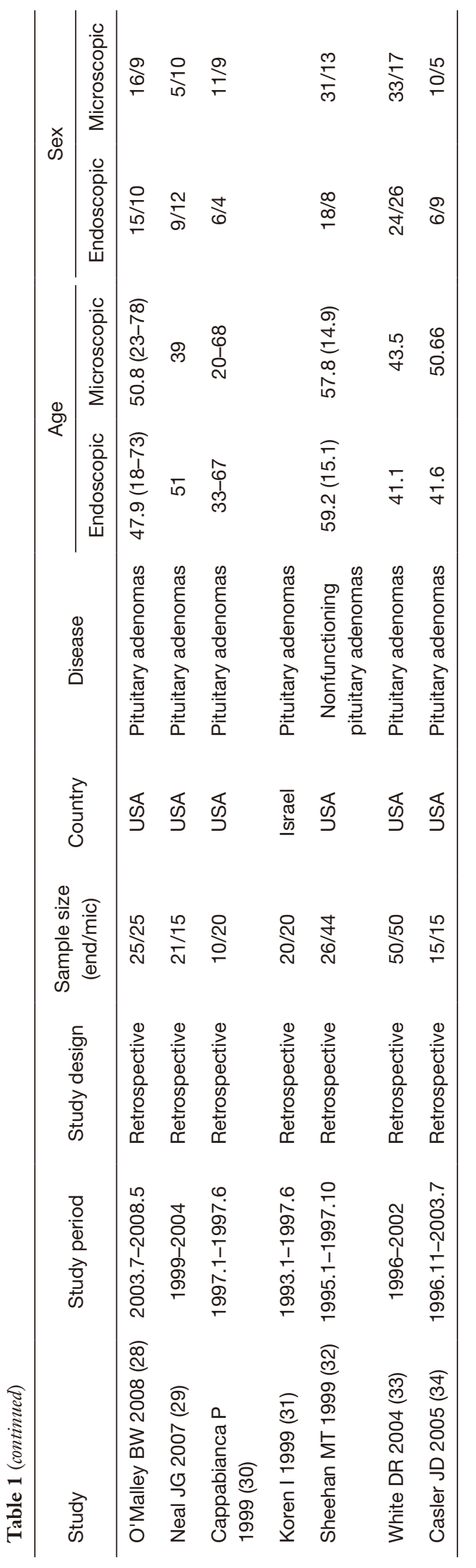

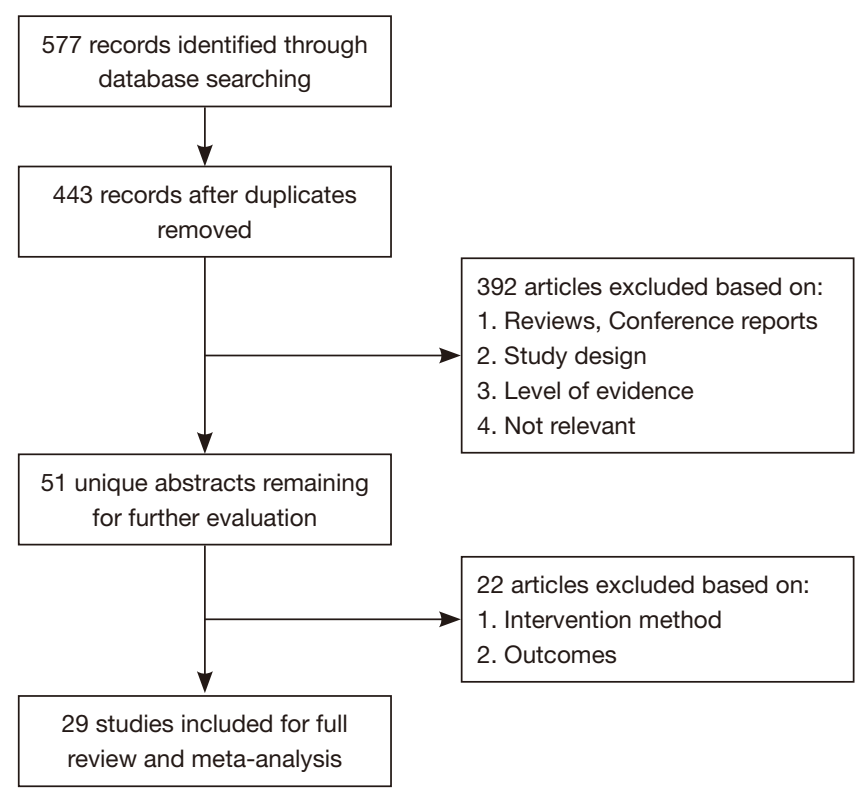

Figure 1 Flow diagram showing the study selection process.

group and the microscopic surgery group $(\mathrm{RR}=1.73,95 \%$ CI: 0.80-3.76, P=0.17, Figure 7).

\section{Meningitis}

Ten studies reported the incidence of postoperative meningitis in patients with pituitary tumors who underwent endoscopic transsphenoidal resection or microscopic transsphenoidal resection. No significant difference was found in the incidence of meningitis between the endoscopic surgery group and the microscopic surgery group (RR $=1.20,95 \%$ CI: $0.68-2.14, \mathrm{P}=0.53$, Figure 8$)$.

\section{Hypothyroidism}

Eight studies reported the incidence of postoperative hypopituitarism in patients with pituitary tumors who underwent endoscopic transsphenoidal resection or microscopic transsphenoidal resection. The results showed no significant difference in the incidence of hypopituitarism between the endoscopic surgery group and the microscopic surgery group $(\mathrm{RR}=0.80,95 \% \mathrm{CI}: 0.55-1.18, \mathrm{P}=0.26$, Figure 9).

\section{Visual improvement}

Five studies analyzed the visual improvement rate in patients with pituitary tumors who underwent endoscopic transsphenoidal resection and microscopic transsphenoidal 


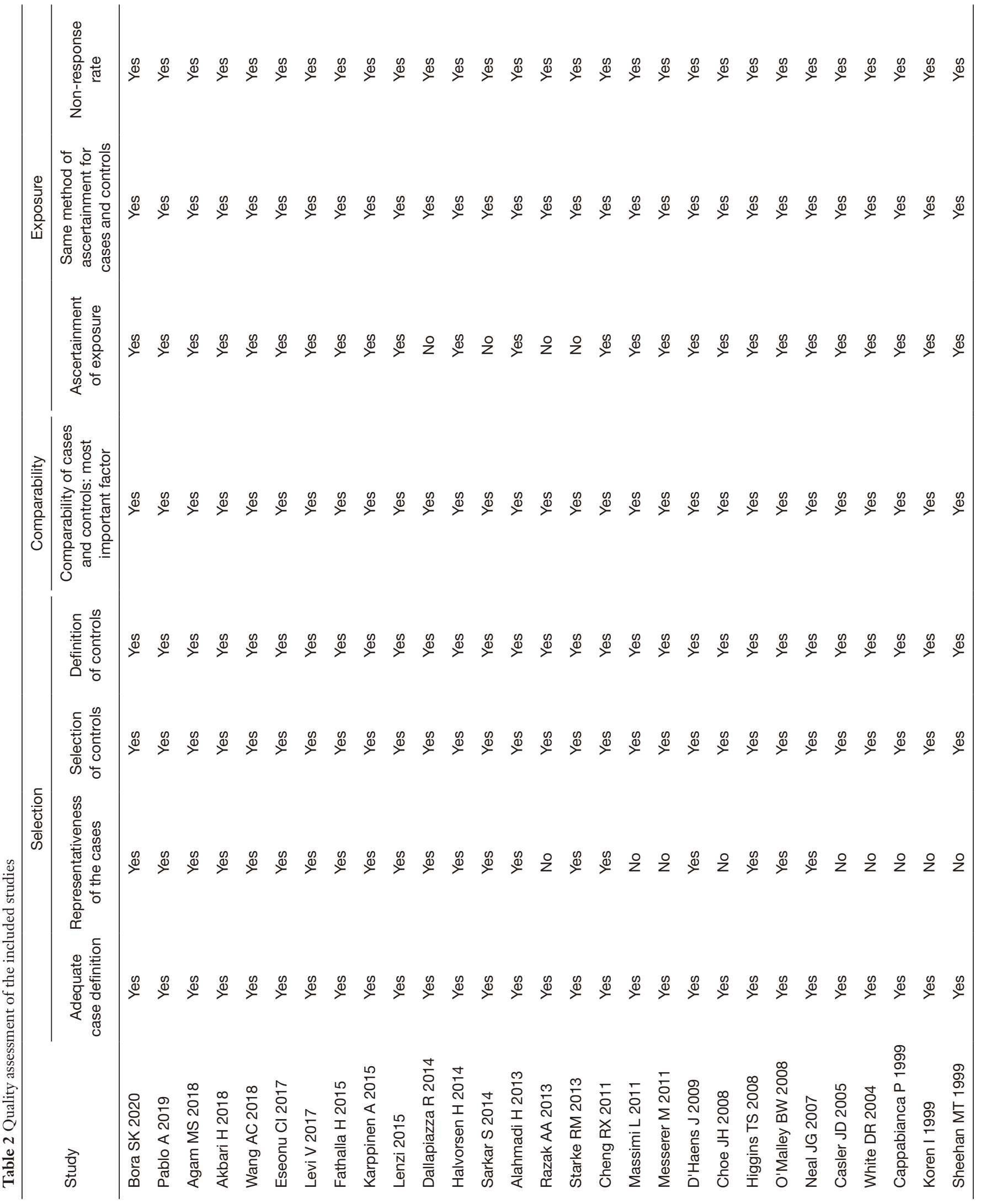




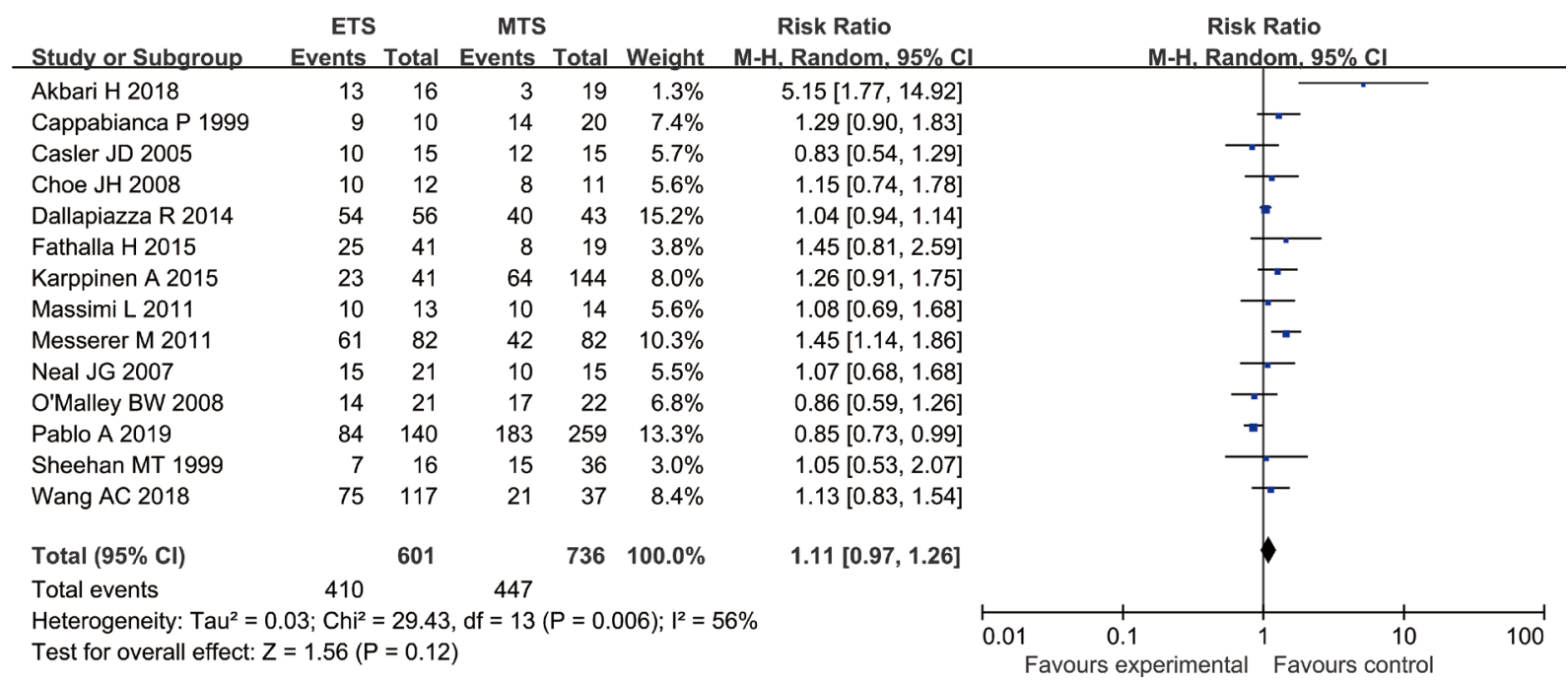

Figure 2 Comparison of gross tumor removal (GTR) between endoscopic transsphenoidal surgery (ETS) and microscopic transsphenoidal surgery (MTS).

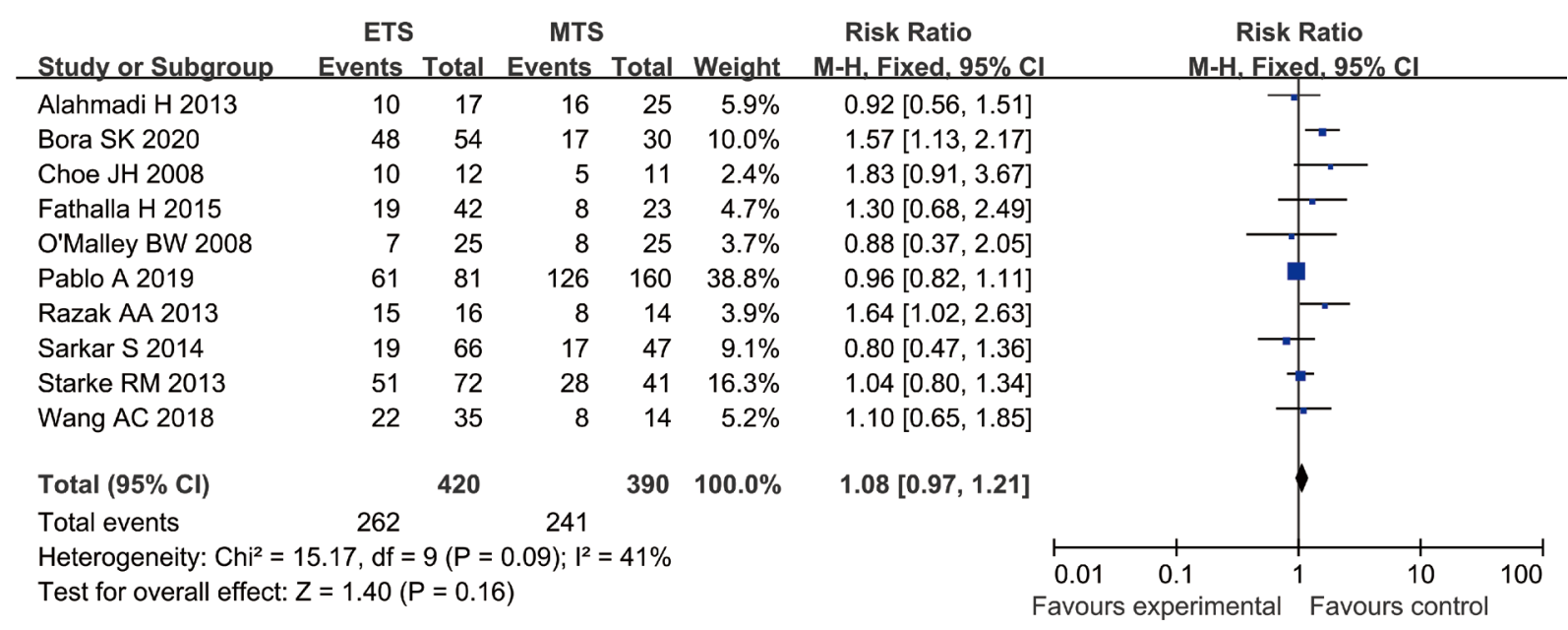

Figure 3 Comparison of the hormone excess secretion (HES) remission rates between endoscopic transsphenoidal surgery (ETS) and microscopic transsphenoidal surgery (MTS).

resection. The results showed that there was no significant difference in the visual improvement rate between the endoscopic surgery group and the microscopic surgery group (RR =1.01, 95\% CI: 0.87-1.17, P=0.89, Figure 10).

\section{Vision loss}

Seven studies reported the incidence of postoperative visual impairment in patients with pituitary tumors who underwent endoscopic transsphenoidal resection or microscopic transsphenoidal resection. The results revealed no significant difference in the incidence of visual impairment between the endoscopic surgery group and the microscopic surgery group ( $\mathrm{RR}=1.05,95 \% \mathrm{CI}$ : $0.56-1.96$, $\mathrm{P}=0.89$, Figure 11).

\section{Publication bias}

The funnel chart showed that no publication bias existed (Figures S1-S10). 


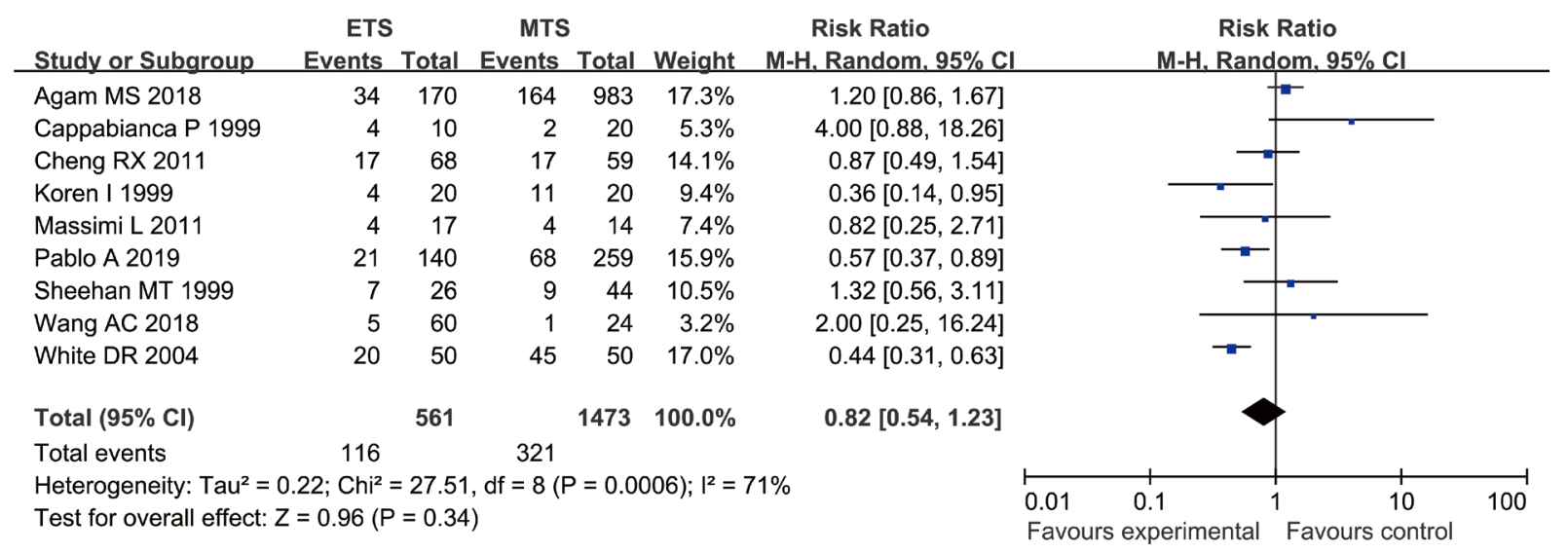

Figure 4 Comparison of the overall complication rates of endoscopic transsphenoidal surgery (ETS) and microscopic transsphenoidal surgery (MTS).

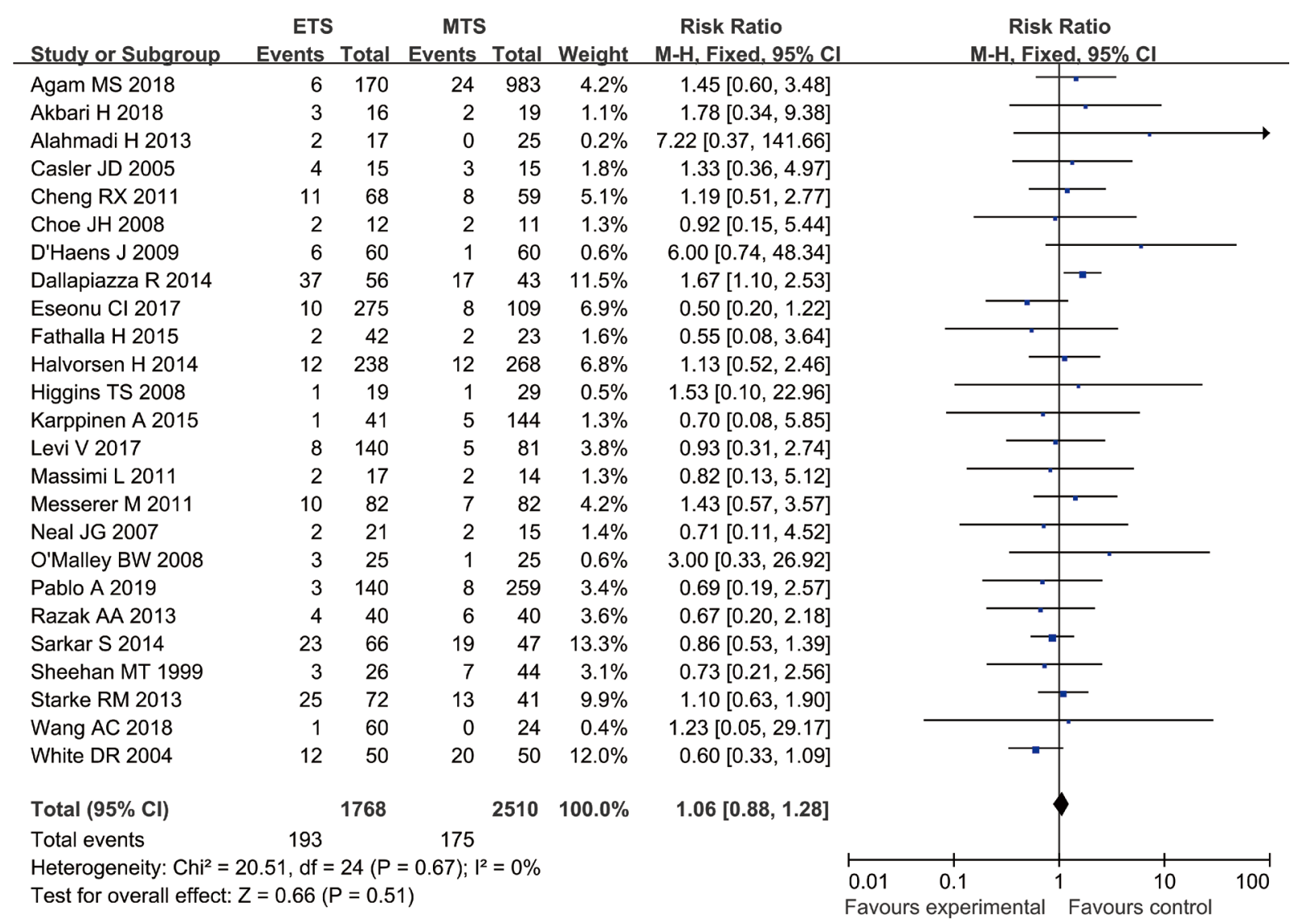

Figure 5 Comparison of the incidence of cerebrospinal fluid (CSF) leakage between endoscopic transsphenoidal surgery (ETS) and microscopic transsphenoidal surgery (MTS). 


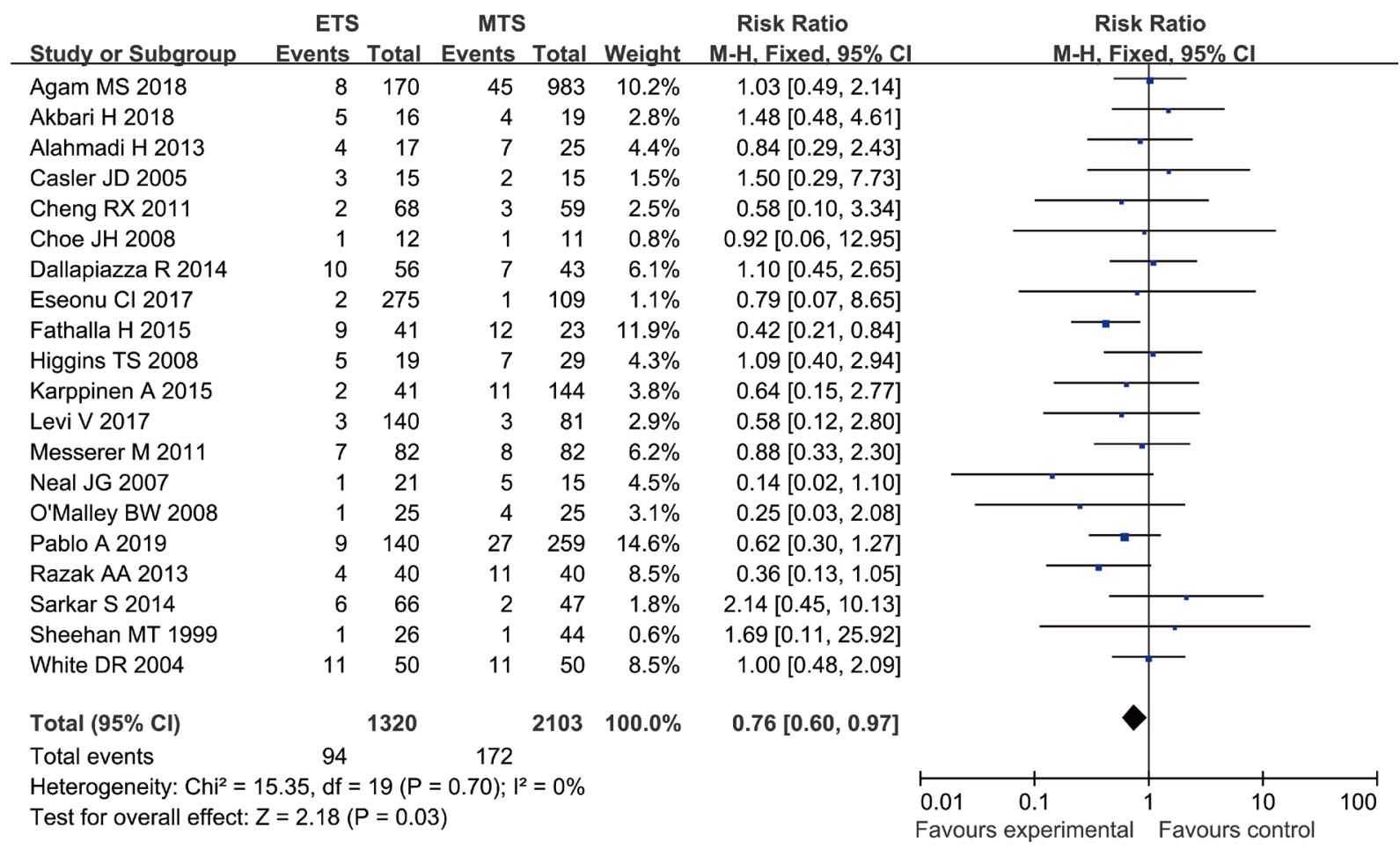

Figure 6 Comparison of the incidence of diabetes insipidus (DI) between endoscopic transsphenoidal surgery (ETS) and microscopic transsphenoidal surgery (MTS).

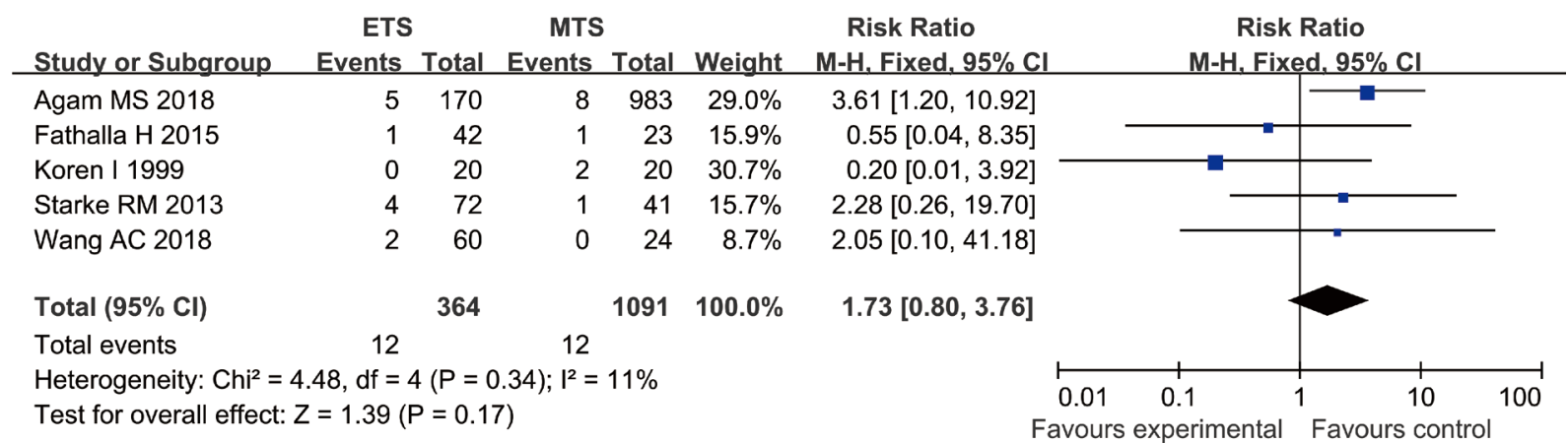

Figure 7 Comparison of the incidence of epistaxis between endoscopic transsphenoidal surgery (ETS) and microscopic transsphenoidal surgery (MTS).

\section{Discussion}

At present, transsphenoidal tumor resection employing a neuroendoscopic or microscopic approach is the standard surgical treatment for pituitary tumors. However, the short-term effects of these two surgical methods are still controversial. In recent years, an increasing number of high-quality clinical studies have been conducted on the application of these two surgical methods in the treatment of pituitary tumors. However, the latest result of evidencebased medicine research has not been updated in time.

This meta-analysis of 29 case-control studies compared the efficacy and safety of neuroendoscopic and microscopic transsphenoidal resection for the treatment of pituitary tumors. The results showed that in terms of clinical efficacy, 


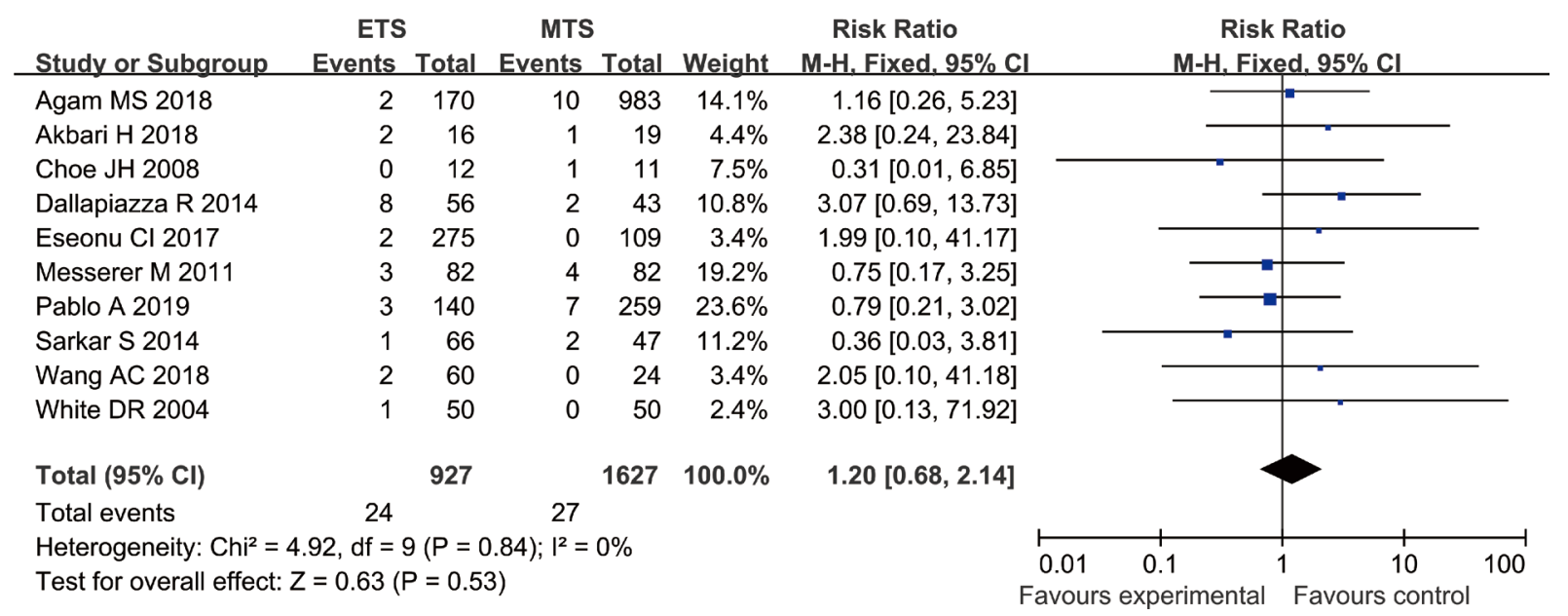

Figure 8 Comparison of the incidence of meningitis between endoscopic transsphenoidal surgery (ETS) and microscopic transsphenoidal surgery (MTS).

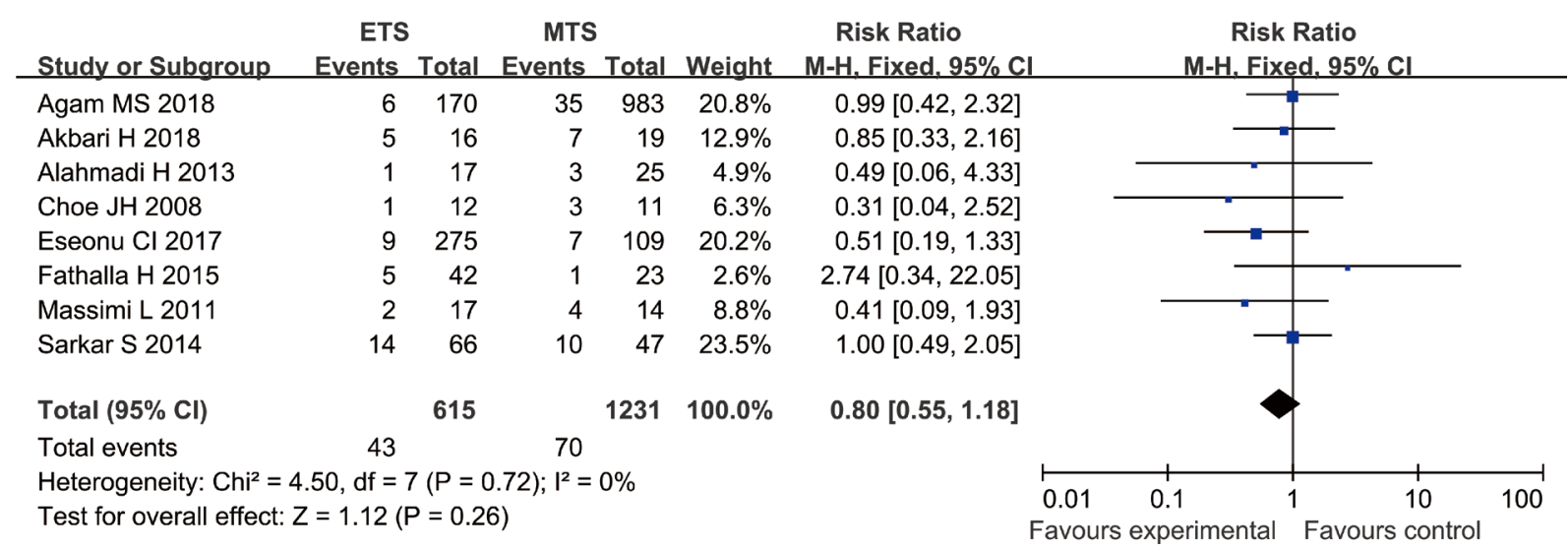

Figure 9 Comparison of the incidence of hypothyroidism between endoscopic transsphenoidal surgery (ETS) and microscopic transsphenoidal surgery (MTS).

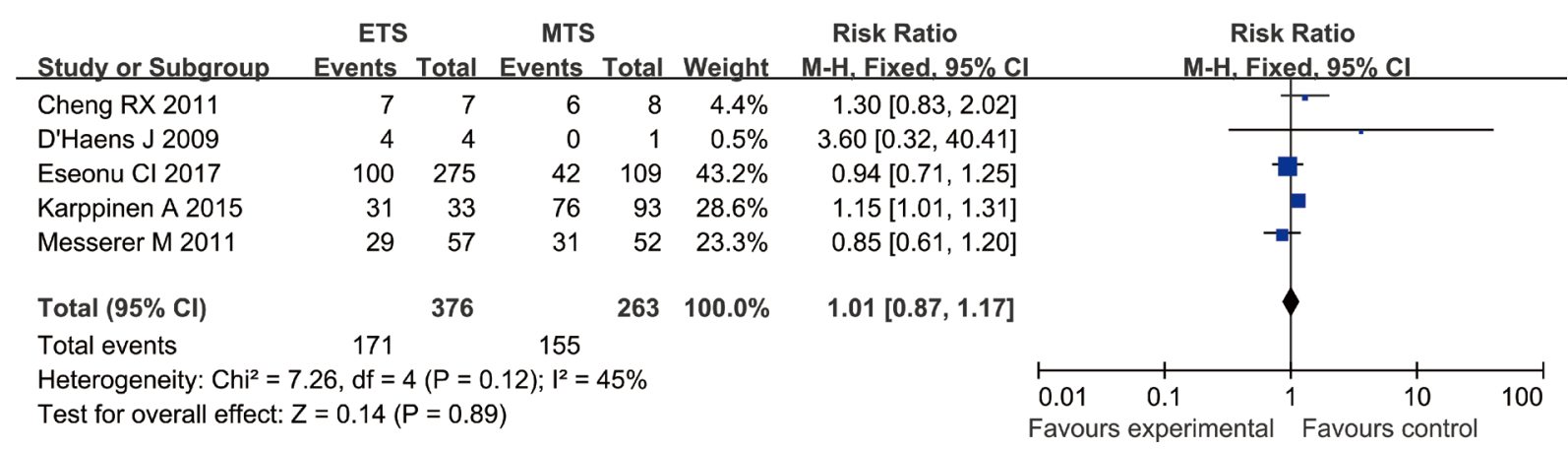

Figure 10 Comparison of the visual improvement rates of endoscopic transsphenoidal surgery (ETS) and microscopic transsphenoidal surgery (MTS). 


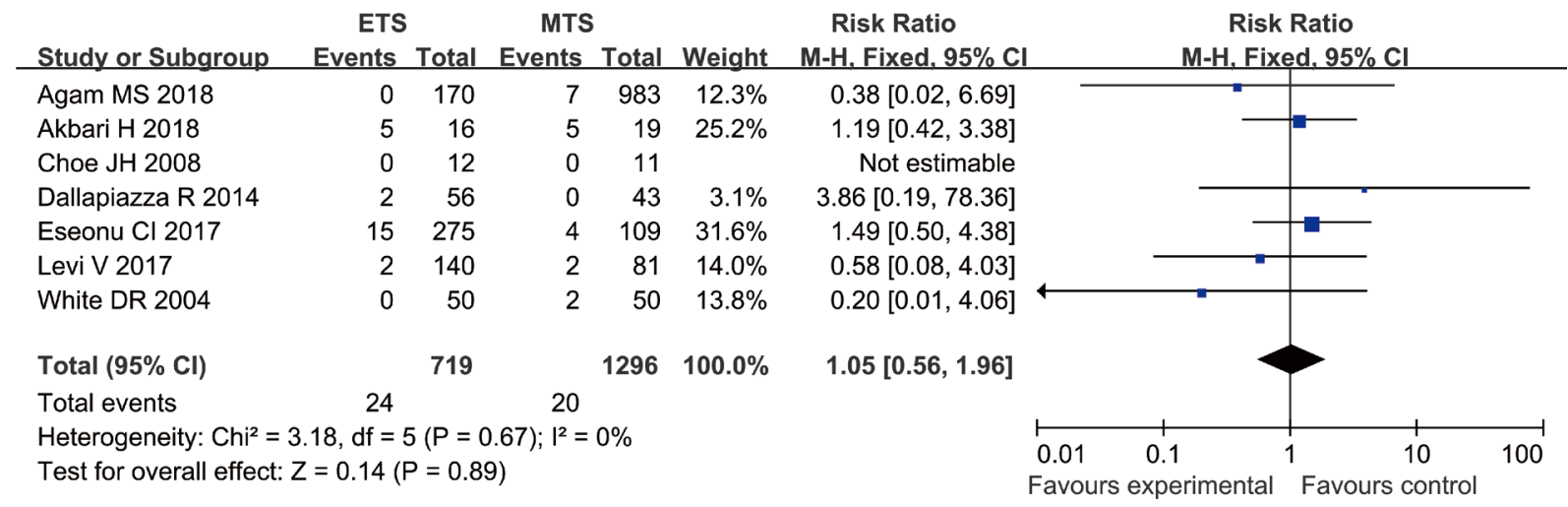

Figure 11 Comparison of the incidence of vision loss between endoscopic transsphenoidal surgery (ETS) and microscopic transsphenoidal surgery (MTS).

there was no statistically significant difference in the rates of tumor total resection, hormone over-secretion, or visual improvement between the two surgical methods. In terms of safety, neuroendoscopic transsphenoidal surgery could significantly reduce the postoperative incidence of DI, although total complications, CSF leakage, epistaxis, meningitis, and other complications did not differ significantly between the two methods.

Although the resection rates of the two techniques did not show a significant difference, the ease of operation of the endoscope is an advantage in more complex operations. The use of an angled endoscope and its large range of movement can facilitate the removal of tumors that cannot be reached using the traditional transsphenoidal approach. Second, due to its flexibility, the endoscope can be inserted into the resected tumor cavity at the end of the operation to look for residual tumor, which makes intraoperative magnetic resonance imaging unnecessary. For large tumors that may be accompanied by CSF leakage, the use of an endoscope offers the advantage of a panoramic field of view.

The postoperative recovery of vision in patients with pituitary tumors is affected by factors including the age of onset, the preoperative degree of visual field defect, tumor size, and other factors. Following surgery, the vision of most patients is improved to varying degrees. However, there is no evidence that the choice of surgical method can affect postoperative recovery of vision, and our results cannot prove this.

Postoperative DI is transient in most cases, and few patients develop permanent DI. The occurrence of DI is affected by the precision of the surgeon. The neuroendoscopic transsphenoidal approach can reduce the incidence of DI, which may be related to the fact that neuroendoscopy can provide a better operative field of view.

CSF leakage is a common postoperative complication. The incidence of CSF leakage for neuroendoscopy and microscopy is $5-7 \%$ and $6.34-8 \%$, respectively. Neuroendoscopy allows the diseased tissue and its surrounding structures, as well as the blind corners of the visual field that cannot be seen under a microscope, to be clearly observed. Therefore, the incidence of postoperative CSF leakage with a neuroendoscope is lower than that with a microscope. However, our results showed no significant difference in the incidence of postoperative CSF fistula between the neuroendoscopic and microscopic surgery groups. There may be three reasons for this: First, the studies we included were all case-control studies with a relatively low level of evidence. Secondly, the number of patients was insufficient. Thirdly, the incidence of postoperative CSF leakage was not significantly affected by the surgical method adopted. This result still needs to be verified by more high-quality large-sample randomized controlled studies.

This study has certain limitations. First, only retrospective case-control studies were included, and most of them did not describe the method for evaluating the tumor total resection rate in detail. The studies also included different types of pituitary tumors, and it was impossible to determine whether postoperative results are correlated with the type of pituitary tumor.

\section{Conclusions}

The results of this meta-analysis suggest that neuroendoscopic 
transsphenoidal surgery does not significantly increase the tumor total resection rate or the remission rate of excessive hormone secretion. However, this surgical method was found to significantly reduce the incidence of postoperative DI without increasing the incidence of other complications.

\section{Acknowledgments}

Funding: None.

\section{Footnote}

Reporting Checklist: The authors have completed the PRISMA reporting checklist. Available at http://dx.doi. org/10.21037/gs-20-851

Conflicts of Interest: All authors have completed the ICMJE uniform disclosure form (available at http://dx.doi. org/10.21037/gs-20-851). The authors have no conflicts of interest to declare.

Ethical Statement: The authors are accountable for all aspects of the work in ensuring that questions related to the accuracy or integrity of any part of the work are appropriately investigated and resolved.

Open Access Statement: This is an Open Access article distributed in accordance with the Creative Commons Attribution-NonCommercial-NoDerivs 4.0 International License (CC BY-NC-ND 4.0), which permits the noncommercial replication and distribution of the article with the strict proviso that no changes or edits are made and the original work is properly cited (including links to both the formal publication through the relevant DOI and the license). See: https://creativecommons.org/licenses/by-nc-nd/4.0/.

\section{References}

1. Yang C, Zhang J, Li J, et al. The role of multimodal navigation in endoscopic endonasal surgery for giant pituitary adenomas. Gland Surg 2019;8:663-73.

2. Wang AJ, Zaidi HA, Laws ED Jr. History of endonasal skull base surgery. J Neurosurg Sci 2016;60:441-53.

3. Jankowski R, Auque J, Simon C, et al. Endoscopic pituitary tumor surgery. Laryngoscope 1992;102:198-202.

4. Laufer I, Anand VK, Schwartz TH. Endoscopic, endonasal extended transsphenoidal, transplanum transtuberculum approach for resection of suprasellar lesions. J Neurosurg
2007;106:400-6.

5. Stang A. Critical evaluation of the Newcastle-Ottawa scale for the assessment of the quality of nonrandomized studies in meta-analyses. Eur J Epidemiol 2010;25:603-5.

6. Bora SK, Suri A, Khadgawat R, et al. Management of Cushing's Disease: Changing Trend from Microscopic to Endoscopic Surgery. World Neurosurg 2020;134:e46-e54.

7. Pablo A, Sofia B, Maximiliano T, et al. Endoscopic versus Microscopic Pituitary Adenoma Surgery: A Single-center Study. Neurol India 2019;67:1015-21.

8. Agam MS, Wedemeyer MA, Wrobel B, et al. Complications associated with microscopic and endoscopic transsphenoidal pituitary surgery: experience of 1153 consecutive cases treated at a single tertiary care pituitary center. J Neurosurg 2018. [Epub ahead of print]. doi: 10.3171/2017.12.

9. Akbari H, Malek M, Ghorbani M, et al. Clinical outcomes of endoscopic versus microscopic trans-sphenoidal surgery for large pituitary adenoma. Br J Neurosurg 2018;32:206-9.

10. Wang AC, Shah AH, Sidani C, et al. Volumetry in the Assessment of Pituitary Adenoma Resection: Endoscopy versus Microscopy. J Neurol Surg B Skull Base 2018;79:538-44.

11. Eseonu CI, ReFaey K, Rincon-Torroella J, et al. Endoscopic Versus Microscopic Transsphenoidal Approach for Pituitary Adenomas: Comparison of Outcomes During the Transition of Methods of a Single Surgeon. World Neurosurg 2017;97:317-25.

12. Levi V, Bertani GA, Guastella C, et al. Microscopic versus endoscopic transsphenoidal surgery for pituitary adenoma: analysis of surgical safety in 221 consecutive patients. Clin Otolaryngol 2017;42:466-9.

13. Fathalla H, Cusimano MD, Di Ieva A, et al. Endoscopic versus microscopic approach for surgical treatment of acromegaly. Neurosurg Rev 2015;38:541-8; discussion 548-9.

14. Karppinen A, Kivipelto L, Vehkavaara S, et al. Transition From Microscopic to Endoscopic Transsphenoidal Surgery for Nonfunctional Pituitary Adenomas. World Neurosurg 2015;84:48-57.

15. Lenzi J, Lapadula G, D'amico T, et al, Gargiulo P. Evaluation of trans-sphenoidal surgery in pituitary GHsecreting micro- and macroadenomas: a comparison between microsurgical and endoscopic approach. J Neurosurg Sci 2015;59:11-8.

16. Dallapiazza R, Bond AE, Grober Y, et al. Retrospective analysis of a concurrent series of microscopic versus endoscopic transsphenoidal surgeries for Knosp Grades 
0-2 nonfunctioning pituitary macroadenomas at a single institution. J Neurosurg 2014;121:511-7.

17. Halvorsen H, Ramm-Pettersen J, Josefsen R, et al. Surgical complications after transsphenoidal microscopic and endoscopic surgery for pituitary adenoma: a consecutive series of 506 procedures. Acta Neurochir (Wien) 2014;156:441-9.

18. Sarkar S, Rajaratnam S, Chacko G, et al. Endocrinological outcomes following endoscopic and microscopic transsphenoidal surgery in 113 patients with acromegaly. Clin Neurol Neurosurg 2014;126:190-5.

19. Alahmadi H, Cusimano MD, Woo K, et al. Impact of technique on cushing disease outcome using strict remission criteria. Can J Neurol Sci 2013;40:334-41.

20. Razak AA, Horridge M, Connolly DJ, et al. Comparison of endoscopic and microscopic trans-sphenoidal pituitary surgery: early results in a single centre. Br J Neurosurg 2013;27:40-3.

21. Starke RM, Raper DM, Payne SC, et al. Endoscopic vs microsurgical transsphenoidal surgery for acromegaly: outcomes in a concurrent series of patients using modern criteria for remission. J Clin Endocrinol Metab 2013;98:3190-8.

22. Cheng RX, Tian HL, Gao WW, et al. A comparison between endoscopic trans-sphenoidal surgery and traditional trans-sphenoidal microsurgery for functioning pituitary adenomas. J Int Med Res 2011;39:1985-93.

23. Massimi L, Rigante M, D'Angelo L, et al. Quality of postoperative course in children: endoscopic endonasal surgery versus sublabial microsurgery. Acta Neurochir (Wien) 2011;153:843-9.

24. Messerer M, De Battista JC, Raverot G, et al. Evidence of improved surgical outcome following endoscopy for nonfunctioning pituitary adenoma removal. Neurosurg Focus 2011;30:E11.

25. D'Haens J, Van Rompaey K, Stadnik T, et al. Fully endoscopic transsphenoidal surgery for functioning

Cite this article as: Chen X, Huang W, Li H, Huan Y, Mai G, Chen L, Huang H, Xu H. Comparison of outcomes between endoscopic and microscopic transsphenoidal surgery for the treatment of pituitary adenoma: a meta-analysis. Gland Surg 2020;9(6):2162-2174. doi: 10.21037/gs-20-851 pituitary adenomas: a retrospective comparison with traditional transsphenoidal microsurgery in the same institution. Surg Neurol 2009;72:336-40.

26. Choe JH, Lee KS, Jeun SS, et al. Endocrine outcome of endoscopic endonasal transsphenoidal surgery in functioning pituitary adenomas. J Korean Neurosurg Soc 2008;44:151-5.

27. Higgins TS, Courtemanche C, Karakla D, et al. Analysis of transnasal endoscopic versus transseptal microscopic approach for excision of pituitary tumors. Am J Rhinol 2008;22:649-52.

28. O'Malley BW Jr, Grady MS, Gabel BC, et al. Comparison of endoscopic and microscopic removal of pituitary adenomas: single-surgeon experience and the learning curve. Neurosurg Focus 2008;25:E10.

29. Neal JG, Patel SJ, Kulbersh JS, et al. Comparison of techniques for transsphenoidal pituitary surgery. Am J Rhinol 2007;21:203-6.

30. Cappabianca P, Alfieri A, Colao A, et al. Endoscopic endonasal transsphenoidal approach: an additional reason in support of surgery in the management of pituitary lesions. Skull Base Surg 1999;9:109-17.

31. Koren I, Hadar T, Rappaport ZH, et al. Endoscopic transnasal transsphenoidal microsurgery versus the sublabial approach for the treatment of pituitary tumors: endonasal complications. Laryngoscope 1999;109:1838-40.

32. Sheehan MT, Atkinson JL, Kasperbauer JL, et al. Preliminary comparison of the endoscopic transnasal vs the sublabial transseptal approach for clinically nonfunctioning pituitary macroadenomas. Mayo Clin Proc 1999;74:661-70.

33. White DR, Sonnenburg RE, Ewend MG, et al. Safety of minimally invasive pituitary surgery (MIPS) compared with a traditional approach. Laryngoscope 2004;114:1945-8.

34. Casler JD, Doolittle AM, Mair EA. Endoscopic surgery of the anterior skull base. Laryngoscope 2005;115:16-24.

(English Language Editor: J. Reynolds) 


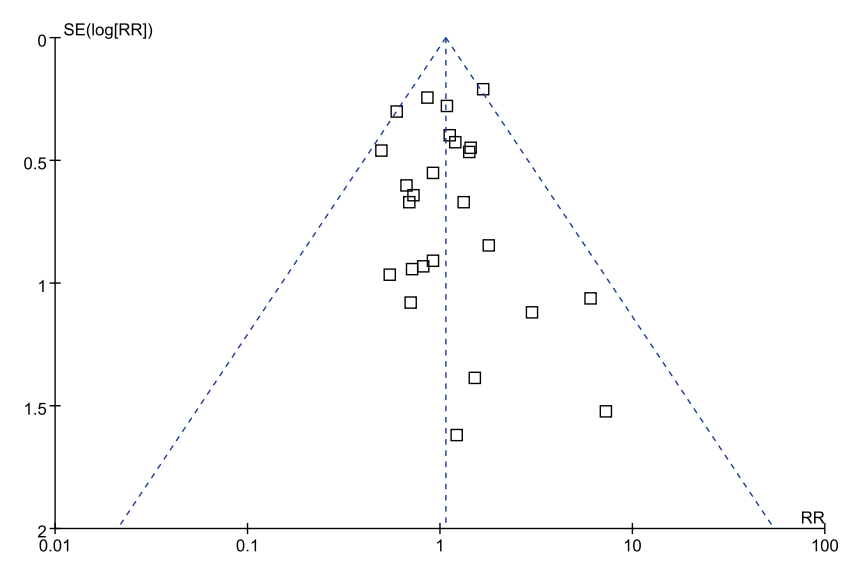

Figure S1 CSF leak Funnel plot.

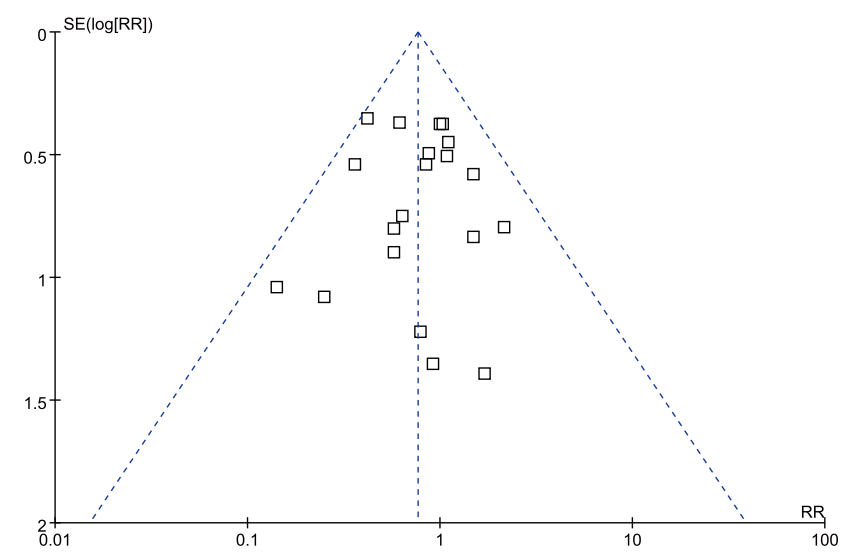

Figure S2 DI Funnel plot.

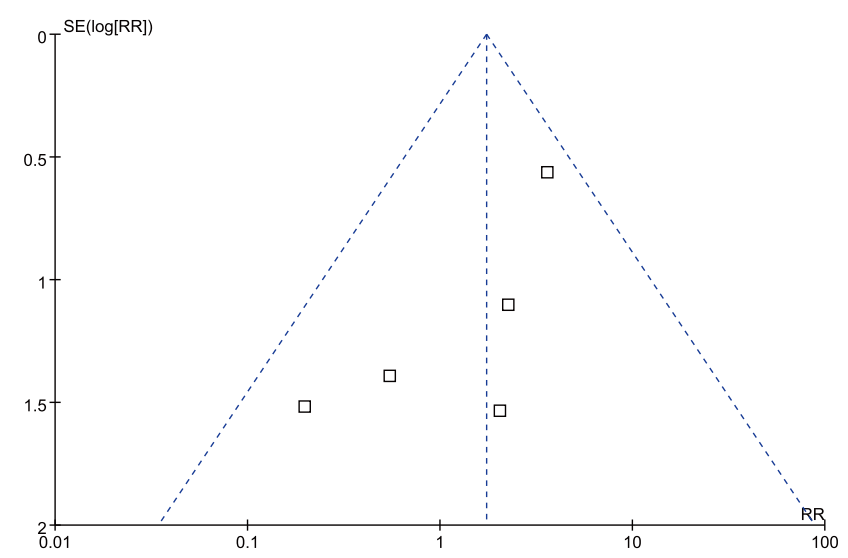

Figure S3 Epistaxis Funnel plot.

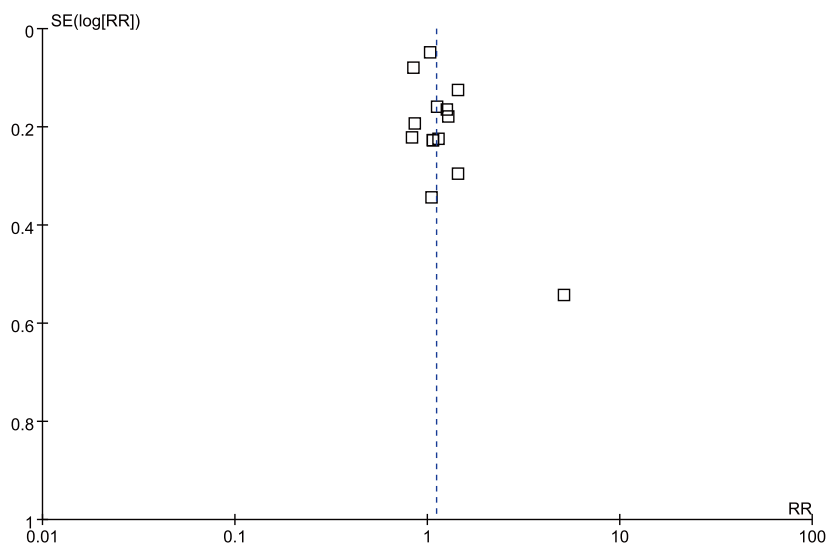

Figure S4 GTR Funnel plot.

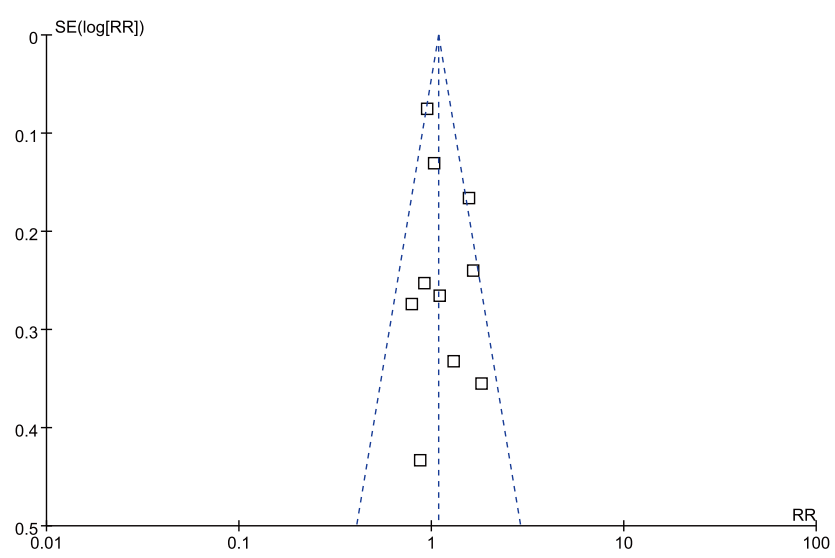

Figure S5 HES remission Funnel plot.

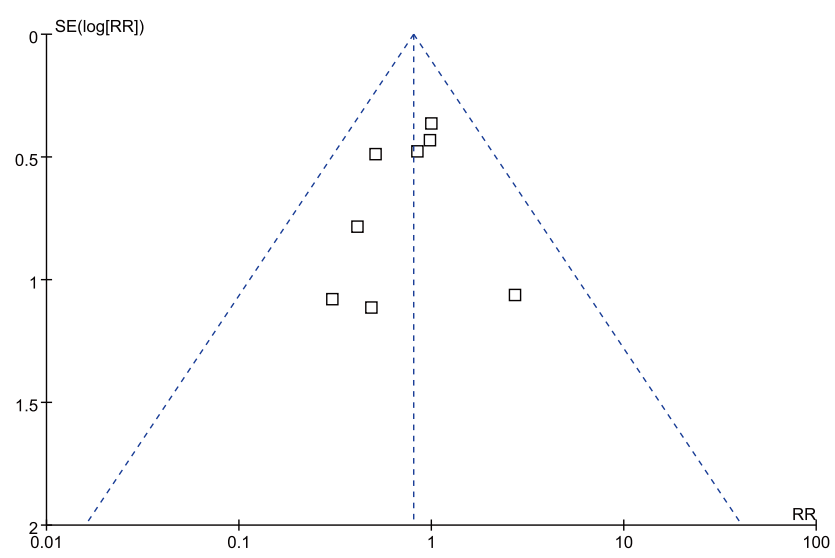

Figure S6 Hypopituitarism Funnel plot. 


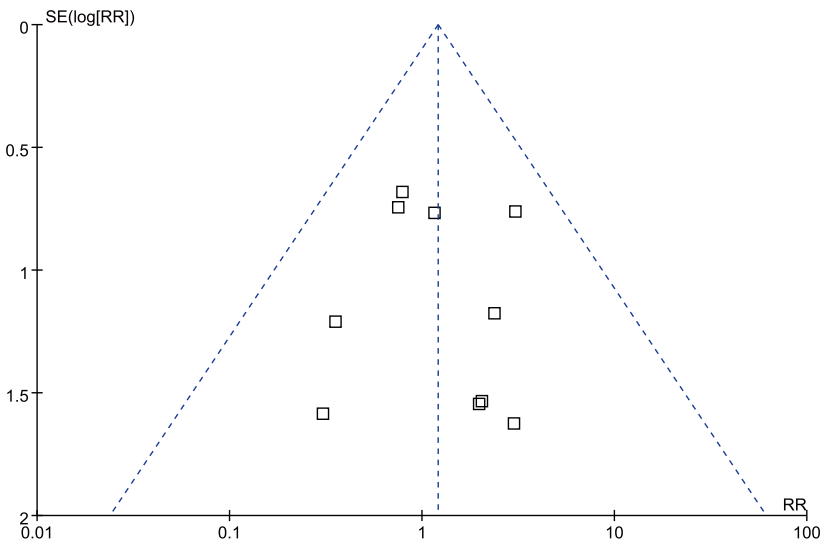

Figure S7 Meningtis Funnel plot.

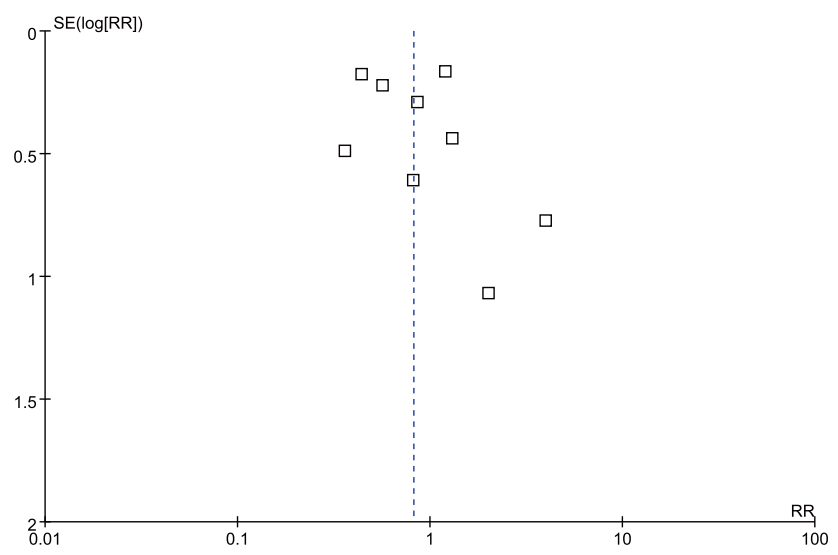

Figure S8 Overall complication Funnel plot.

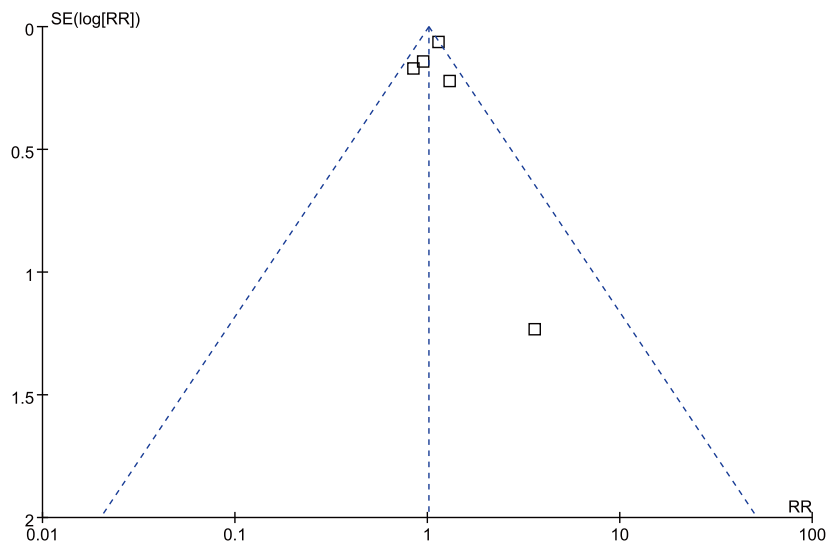

Figure S9 Visual improvement Funnel plot.

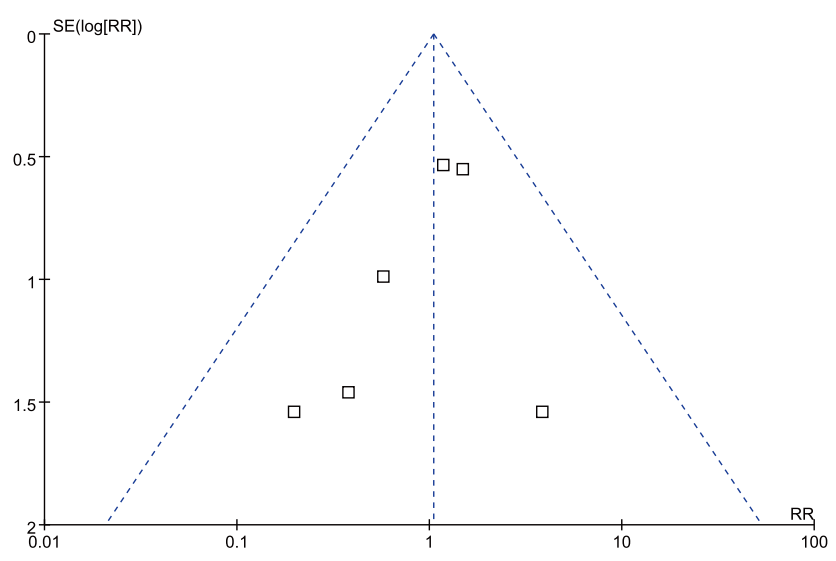

Figure S10 Worsened vision Funnel plot. 